\title{
Patch Antenna Miniaturization Using CSRR
}

\author{
Varindra Kumar \\ Department of Engineering, University of Cambridge, Cambridge, UK \\ Email: Varindra@ieee.org
}

How to cite this paper: Kumar, V. (2017) Patch Antenna Miniaturization Using CSRR. Open Journal of Antennas and Propagation, 5, 132-150. https://doi.org/10.4236/ojapr.2017.53011

Received: August 28, 2017

Accepted: September 24, 2017

Published: September 27, 2017

Copyright $\odot 2017$ by author and Scientific Research Publishing Inc. This work is licensed under the Creative Commons Attribution International License (CC BY 4.0).

http://creativecommons.org/licenses/by/4.0/ (c) (i) Open Access

\begin{abstract}
A novel metamaterial structure has been proposed for Electromagnetic Compatibility (EMC) applications. A patch antenna with dimension of $18 \mathrm{~mm} \times$ $13.9 \mathrm{~mm}$ and resonating at $5 \mathrm{GHz}$ has been designed and the effect of Double Negative (DNG) metamaterial loading for the patch size reduction as well as a lowering in resonance frequency for the fixed size patch antenna has been proposed. A size reduction of $72.5 \%$ in the patch antenna has been obtained with the loading of this metamaterial structure and the effect of loading the metamaterial shows that without reducing the size, the patch antenna can work at $3.7 \mathrm{GHz}$ resonance, providing a lowering in resonance frequency by $26 \%$. The metamaterial structure consists of two concentric loops with an outer radius of $3.1 \mathrm{~mm}$. The width of the ring is $1.0 \mathrm{~mm}$ and the split is 0.5 $\mathrm{mm}$ and has been designed over a $1.57 \mathrm{~mm}$ thick Fr4 substrate. The bending effect of the patch antenna with and without metamaterial loading and its comparison with the planar patch antenna has been also shown here. The metamaterial structure has shown its resonance at $5 \mathrm{GHz}$ and its permittivity and permeability behavior over the desired frequency range has been plotted. The simulation of traditional patch antenna and patch antenna over metamaterial has been compared for its return loss, VSWR, gain and efficiency. Finally, a spice circuit for the S parameter of the metamaterial, patch antenna and patch antenna loaded with metamaterial has been obtained using Matlab and ADS for its equivalence to 3D field solver and its comparison has been plotted for its verification.
\end{abstract}

\section{Keywords}

DNG Metamaterial, CSRR, 5 GHz, Patch, Spice, Planar, Bend

\section{Introduction}

During the last few years, there has been a significant increase in portable electronics devices and these are often interconnected through wireless media within 
a range of operating frequency including $2.4 \mathrm{GHz}$ and $5 \mathrm{GHz}$. The portable electronics are driving the recent miniaturization of every component of the system with the design of small, compact and low profile antennas using conductive patch placed over a substrate. Microstrip patch antenna is one type of patch antenna and has been designed for its low profile, compact size, its integration, low cost and ease of its fabrication. However, electronic devices are getting smaller in size and are creating further demand for a reduction in antenna size. Although traditional patch antennas are small, they are still in the order of half-wavelength and this is not small enough for the current application. Many miniaturization techniques such as high permittivity substrate [1], dielectric loading [2], shorting pins [3] and slots [4] have been applied in the past to miniaturize the size, but these techniques bring additional side effects such as shift in resonance frequency, reduction in efficiency, gain, bandwidth etc. and have not been very successful in their intended requirement. A metamaterial also known as artificial material allows the antenna dimension to be miniaturized with its application at ground layer and still maintaining the antenna performance. Here the metamaterial structure provides negative permittivity and permeability within the intended frequency band and thus the patch antenna designed over metamaterial supporting negative refractive index (NRI) can resonate at its sub wavelength [5] [6] [7]. Many previous works have illustrated the application of metamaterial for its electromagnetic behavior where the direction of wave travel is opposite to the phase velocity, suggesting the use of it for antenna applications [2] [8] [9] [10]. This provides a scope to reduce the patch antenna size for its intended frequency or the patch itself can resonate at its subwavelength without increasing the size. The metamaterial structure can take a shape of various forms of split ring resonator (SRR), metallic thin wires or artificial material with fractal space. This paper presents a design and simulation work on complementary split ring resonator (CSRR) based design for its resonance in the desired frequency region of 5.0 $\mathrm{GHz}$, a Microstrip patch antenna design for $5.0 \mathrm{GHz}$ and miniaturization of this patch antenna (with a dimensional space reduction of $72 \%$ in the patch size) with the loading of metamaterial ring resonator while providing a comparable gain, efficiency and bandwidth. The paper also presents the effect of metamaterial on the resonance frequency where a reduction in its resonance frequency (from $5 \mathrm{GHz}$ to $3.7 \mathrm{GHz}$ ) is observed without an increase in the size of the patch. The bending effects of the antenna with and without metamaterial have also been shown in the paper for its effect on overall gain, efficiency and bandwidth. The equivalent transfer function has been obtained for the $S$ parameters using Matlab (R2016a) and ADS (2012.08) and spice circuit has been obtained for its equivalence against the $3 \mathrm{D}$ field solver results. The spice circuit RLGC parameters calculation provides a mechanism to integrate the antenna design and its parametric calculation using traditional spice circuit solver tools. Overall, the paper has been divided into following sections: Section 1 for Introduction, Section 2 for CSRR design, Section 3 for patch antenna and the effect of loading 
metamaterial in the patch size reduction, Section 4 for patch antenna and its bend effect, Section 5 for patch antenna and resonance frequency shift with the loading of metamaterial structure and finally Section 6 for simulation results and its comparison. The spice circuit provides a convenient mechanism to build and verify any electrical circuit, however, the antenna design in the present $3 \mathrm{D}$ space cannot be integrated within a spice tool. The Spice circuit for the CSRR metamaterial structure, antenna when loaded with metamaterial and antenna without loading metamaterial has been extracted and the method to extract the spice circuit parameters has been described in their respective sub-sections.

\section{CSRR Design}

Any electromagnetic material can be identified by its dielectric permittivity " $\varepsilon$ " and magnetic permeability " $\mu$ " and it belongs to one of the group defined in Figure 1. A metamaterial structure provides unique property for its electromagnetic response with its negative dielectric permittivity " $\varepsilon$ " and negative magnetic permeability " $\mu$ ". The metamaterial structure such as SRR was proposed by Pendry et al. [2] for its Left Hand Material (LHM) studies, this led to the beginning in the design and demonstration for CSRR based electromagnetic applications [11] [12] [13] [14]. The structure is formed by two concentric rings with splits at its opposite at the inner and outer rings.

A LHM metamaterial also known as NRI metamaterial structure supports both forward energy flow and backward wave propagation at the same time, providing a phase shift of $180^{\circ}$ in phase $\left(v_{p}\right)$ and group velocity $\left(v_{g}\right)$ [3]. The NRI

\begin{tabular}{c|c}
$\varepsilon<0, \mu>0$ & $\varepsilon>0, \mu>0$ \\
$\begin{array}{c}\text { Plasmas (ENG) } \\
\text { Dielectrics }\end{array}$ \\
$\begin{array}{l}\text { Metamaterials } \\
\text { (DNG) }\end{array}$ & $\begin{array}{c}\text { Gyrotropic (MNG) } \\
\end{array}$
\end{tabular}

Figure 1. Classification of materials.

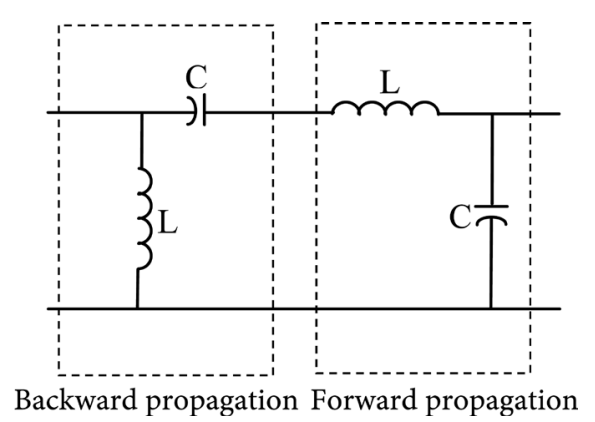

Figure 2. Metamaterial structure equivalence. 

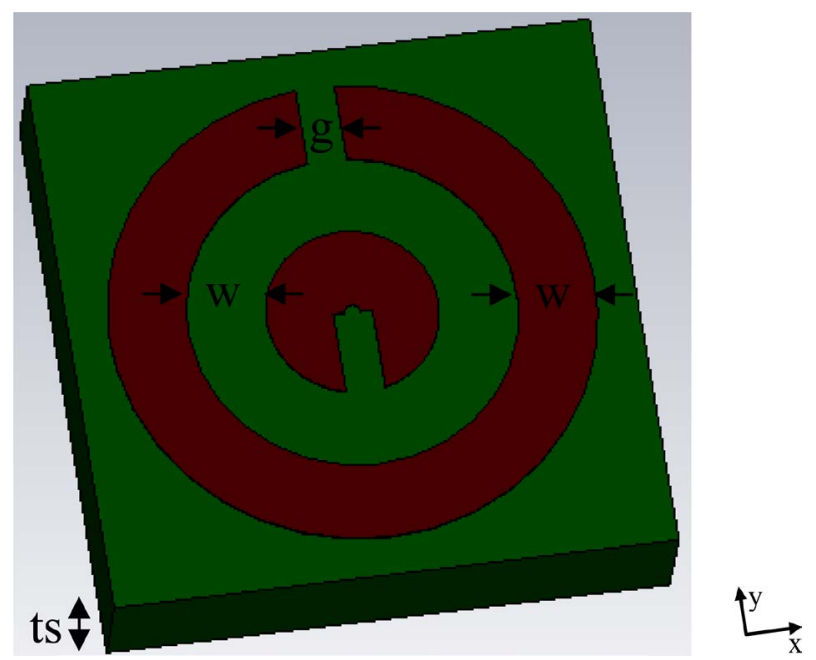

Figure 3. CSRR structure.

structure can be represented by a Left Handed (LH) material however the parasitic effect of the media supports the ordinary Right handed (RH) wave propagation at higher frequency. An equivalent circuit of the NRI material as a combination of LH and RH metamaterial, can be represented using an equivalent circuit of Figure 2 where one portion of the circuit represents the backward propagation of the wave (as LHM) while another portion represents a forward wave propagation (as RHM). Concentric rings as shown in Figure 3 has been designed over Fr4 substrate (dielectric constant of 4.4 and tangent loss of 0.02 ) with dimension of $7.2 \mathrm{~mm} \times 7.2 \mathrm{~mm} \times 1.57 \mathrm{~mm}$. Outer as well as inner ring has been designed with a copper thickness "ts" of $0.017 \mathrm{~mm}$, the outer ring has radius " $R$ " of $3.1 \mathrm{~mm}$ while the width " $w$ " of the ring is $1.0 \mathrm{~mm}$ and split gap " $\mathrm{g}$ " is $0.5 \mathrm{~mm}$. Full field solver tool CST microwave studio is used to design the model and get the simulation results. Using the individual ring dimension and taking an average of the inductance with the sum of capacitance across two rings, an approximate resonance frequency is obtained for the concentric rings with the analytical formula defined using (1) and (2) [15]. Although the analytical calculation using ( 1 - 5) results in $4.8775 \mathrm{GHz}$ resonant frequency while the full field solver tool provides the resonance frequency of $5 \mathrm{GHz}$, the difference can be attributed to the simplicity in the formula representation by using lumped elements.

$$
\begin{gathered}
L_{\text {ring }}=\mu_{0} * R *[\log (8 * R /(t s+\text { width }))-0.5] \\
C_{\text {surf }}=2 * \varepsilon_{0} *((t s+\text { width }) / p i) * \log (4 * R / \text { gap }) \\
C_{\text {gap }}=\varepsilon_{0} *\left(t_{s} * \text { width }\right) / \text { gap }+\varepsilon_{0} *(t s+\text { gap }+ \text { width }) \\
C_{\text {ring }}=C_{\text {surf }}+C_{\text {gap }} \\
f_{\text {res }}=1 /((2 * \text { pi } \\
\text { * } \left.\left.L_{\text {ring } 12} * C_{\text {ring } 12}\right) * \operatorname{sqrt}\left(\left(\varepsilon_{r}+1\right) / 2\right)\right)
\end{gathered}
$$

For the simulation purpose, the CSRR structure is embedded in a TEM wave- 
guide with PEC and PMC conditions applied on its orthogonal wall while the structure is excited along $\mathrm{x}^{-}$direction using an electric field. The return and transmission loss of the CSRR structure has been plotted and shown in Figure 4. The relative permittivity and permeability parameters of the unit cell has also been calculated and shown in Figure 5 and Figure 6 . As seen from Figure 5 and

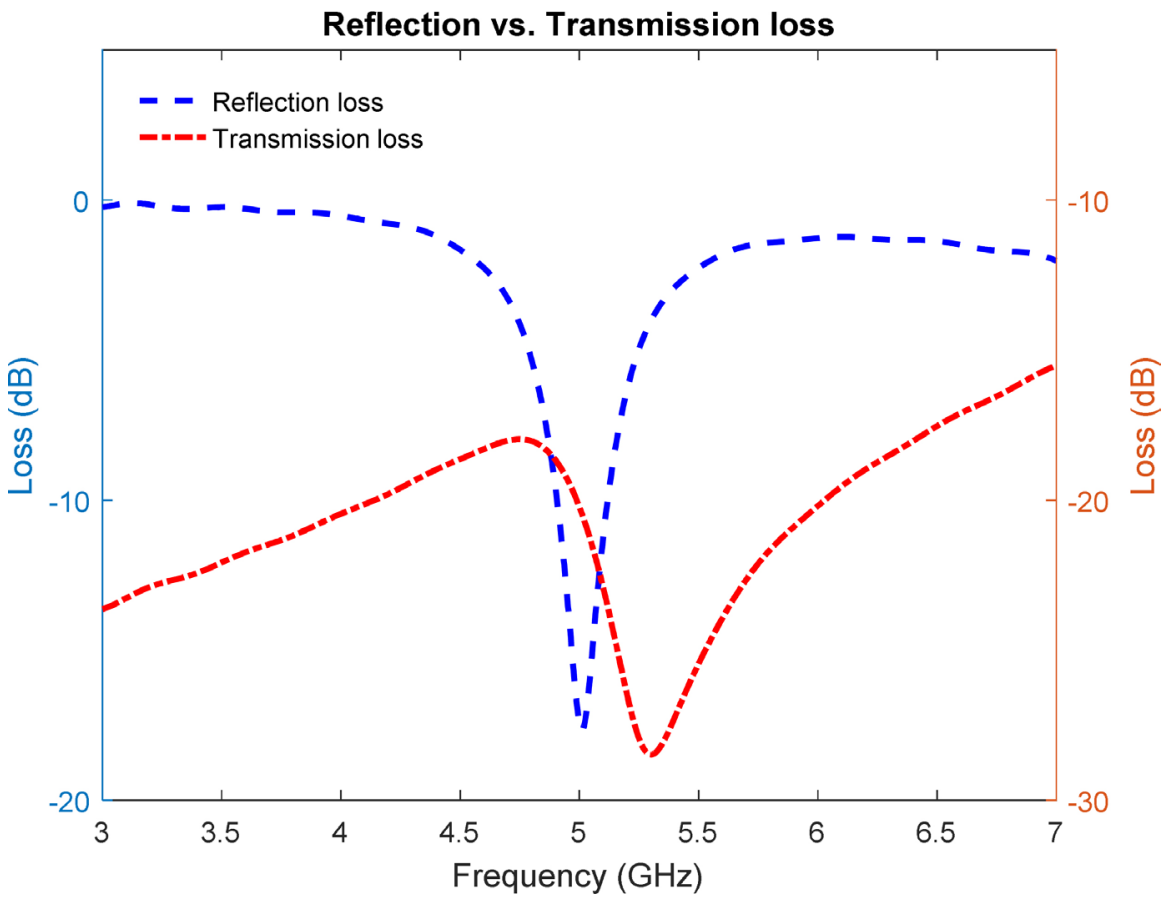

Figure 4. Return vs. Transmission loss.

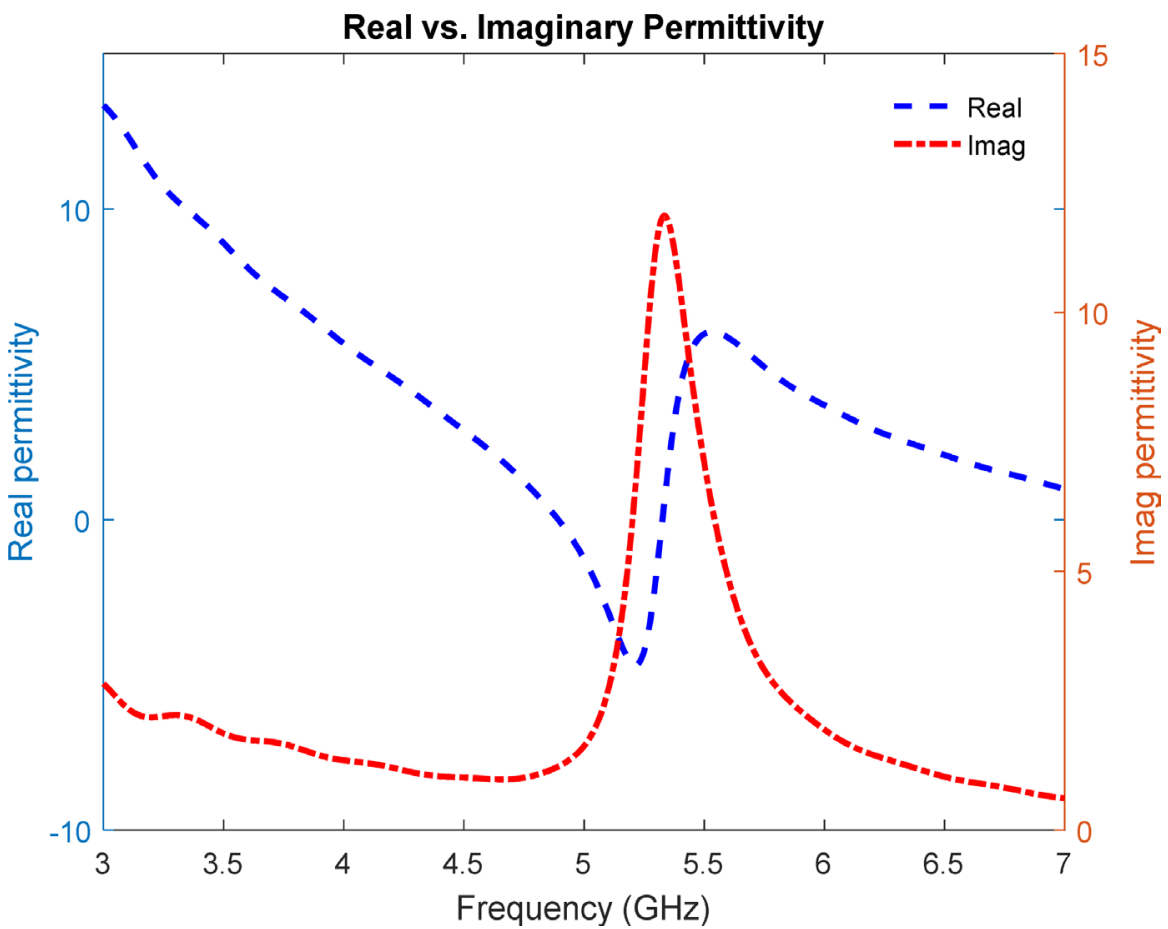

Figure 5. Permittivity plot. 


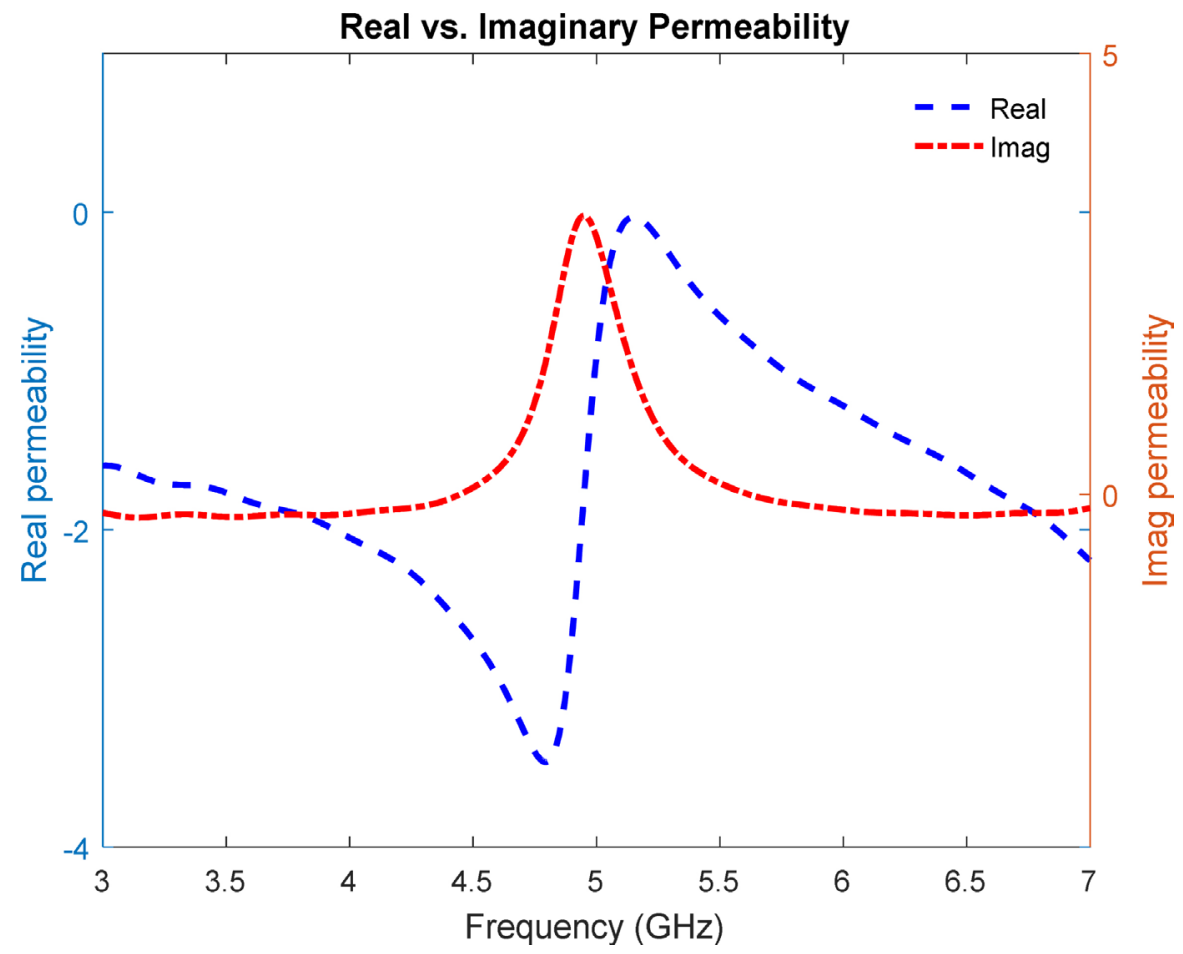

Figure 6. Permeability plot.
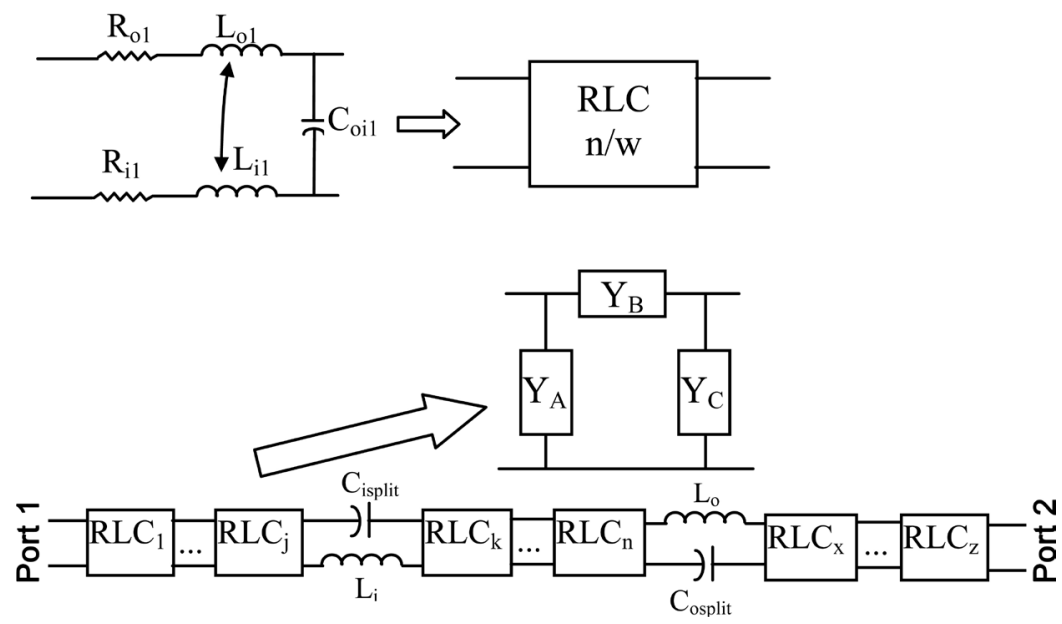

Figure 7. Spice circuit for CSRR.

Figure 6, these parameters are negative within its frequency band, hence the designed structure can be classified as Double Negative (DNG) metamaterial.

The spice circuit provides a method to electrically interface an electronic structure and provide time/frequency response without the need of costly field solver tools. An equivalent spice circuit element for the CSRR can be obtained using series RLC network by segmenting the ring in unit cells, it has been shown in Figure 7 [16]. However the split of the individual ring can be defined by the split capacitance. Since there are two concentric rings, there are capacitive and inductive coupling elements between these two rings as well. Here $R_{o}, L_{o}$ and $R_{i}$, $\mathrm{L}_{\mathrm{i}}$ are the resistive, inductive part of the outer and inner ring, the capacitive part 
between two rings is defined as $\mathrm{C}_{\mathrm{oi}}$. The Matlab based rational fit algorithm [17] as defined using (6) provides an efficient method to extract poles and residues within reasonable iterations to approximately represent the $S$ parameters. Here $\mathrm{P}_{\mathrm{i}}$ and $\mathrm{Z}_{\mathrm{i}}$ are complex poles and residues with an order " $\mathrm{N}$ " while constants $\mathrm{d}$ and $s$ are constant terms and $e$ is the proportionality term. The function can be realized by means of RLC elements with a rational approximation of admittance. After deriving s-parameters, $\mathrm{ABCD}$ parameters can be found out and can be converted into admittance form.

$$
H(S)=\sum_{i=1}^{N}\left(\frac{Z_{i}}{S-P_{i}}\right)+d+s e
$$

The derived rational function is correlated with its admittance and RLC values can be calculated. The equivalent spice circuit for the CSRR has been shown in Figure 7 while Table 1 shows the extracted poles and residues obtained from rational function using Matlab. ADS tool has been also used to extract the spice parameters using its inherent spice extraction mechanism when the passivity is enforced. Due to complexity in the representation of RLC stages (ADS tool extracts the spice circuit with more than ten numbers of RLC stage), only S parameter plot has been shown in Figures 8-11. The exact spice circuit mechanism

Table 1. Poles and Residues for CSRR.

\begin{tabular}{cl}
\hline Poles $(\mathrm{x} 1 \mathrm{e} 10)$ & Residues $(\mathrm{x} 1 \mathrm{e} 10)$ \\
\hline$-6.0747+0.0000 \mathrm{i}$ & $-7.9533+0.0000 \mathrm{i}$ \\
$-0.8476+4.8507 \mathrm{i}$ & $1.1737-0.1724 \mathrm{i}$ \\
$-0.8476-4.8507 \mathrm{i}$ & $1.1737+0.1724 \mathrm{i}$ \\
$-0.2065+3.1408 \mathrm{i}$ & $0.1480-0.2013 \mathrm{i}$ \\
$-0.2065-3.1408 \mathrm{i}$ & $0.1480+0.2013 \mathrm{i}$ \\
\hline
\end{tabular}

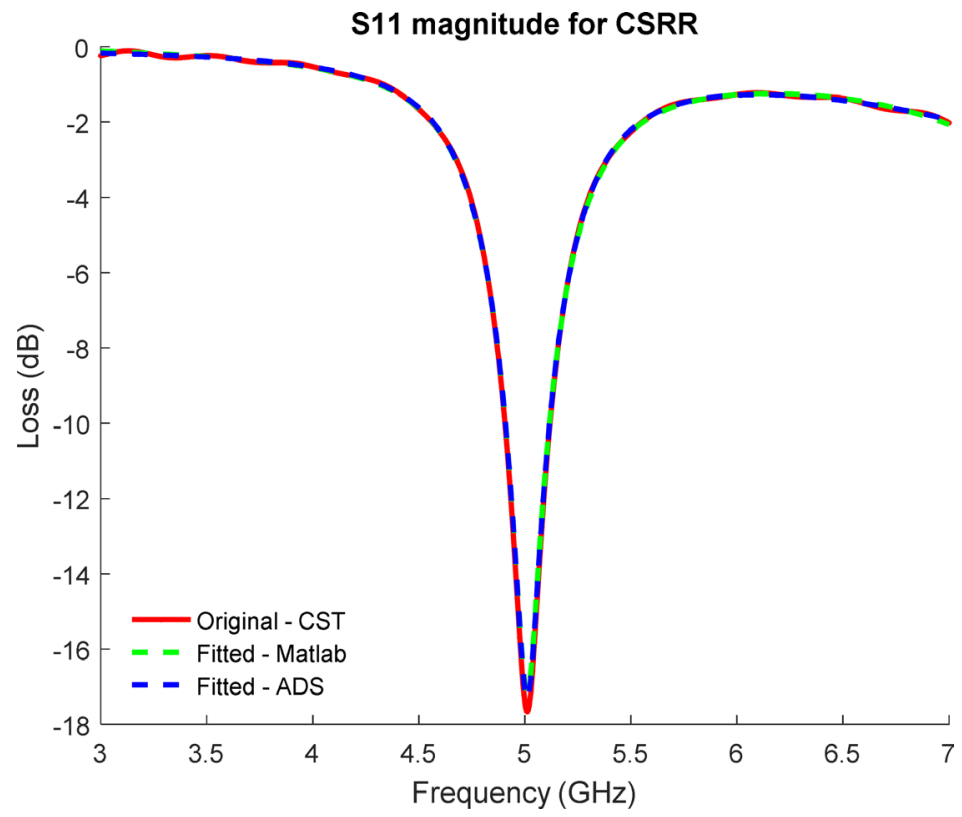

Figure 8. S11 original and fitted magnitude. 


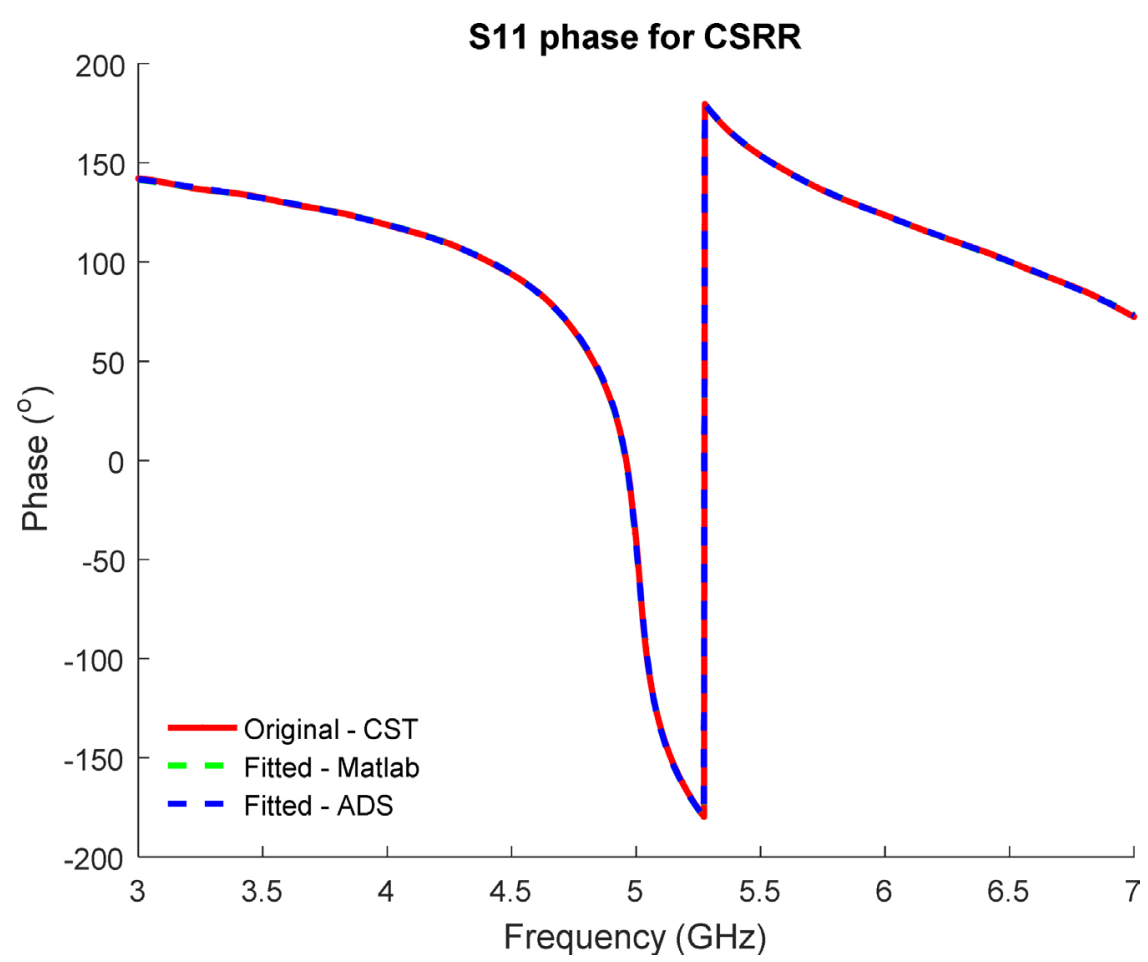

Figure 9. S11 original and fitted phase.

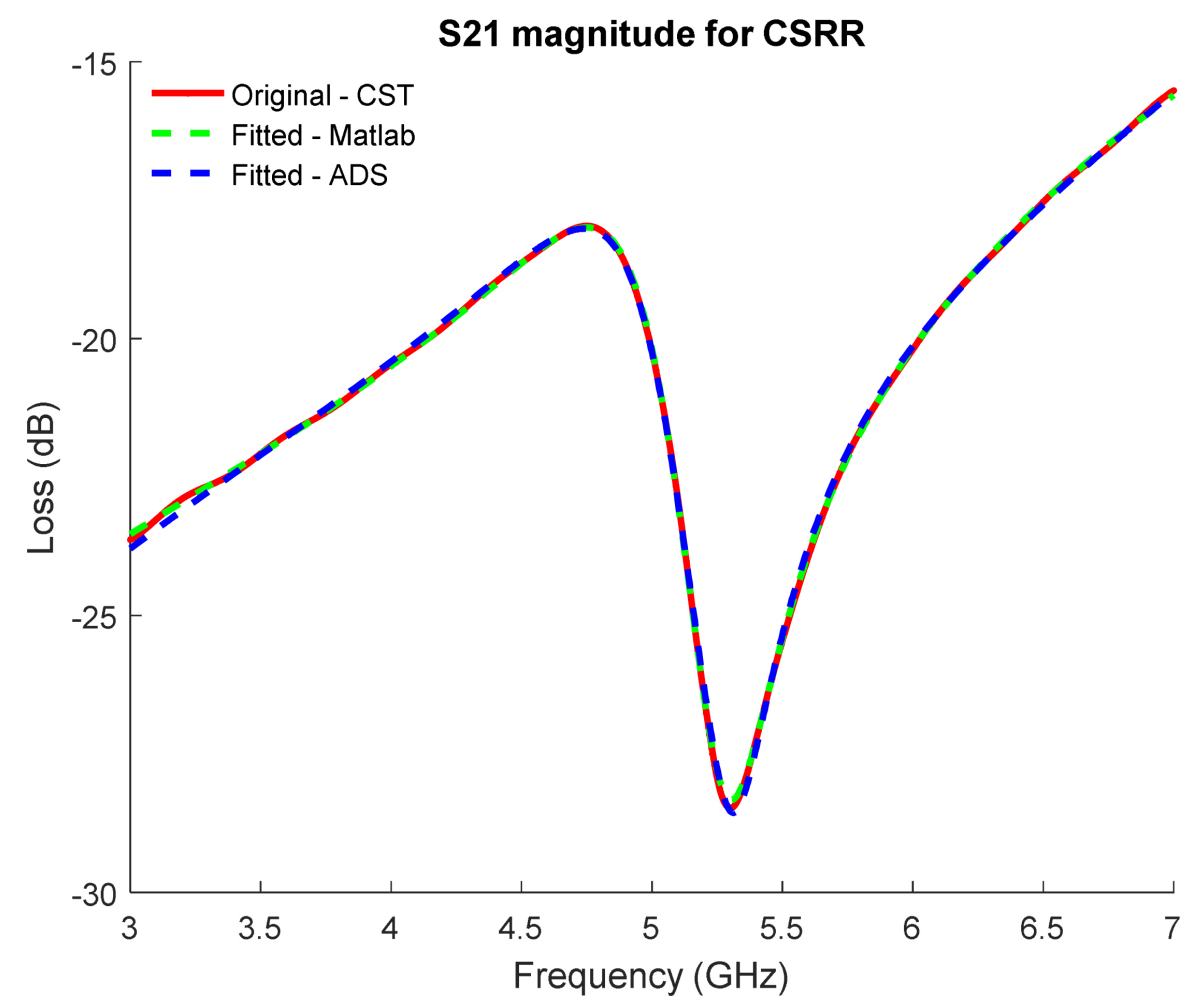

Figure 10. S21 original and fitted magnitude. 


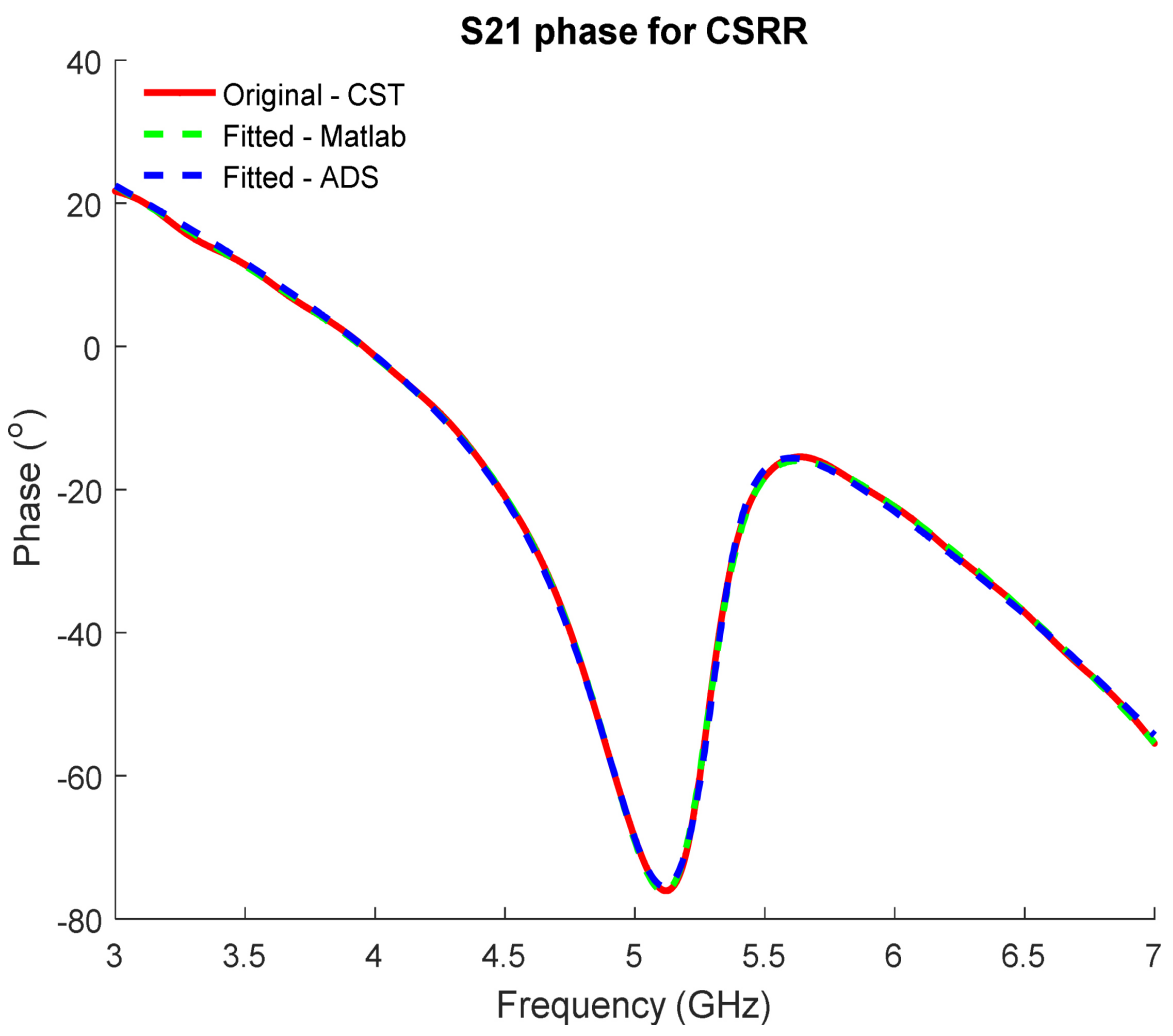

Figure 11. S21 original and fitted phase.

remains similar to the presentation in Figure 7. In the subsequent subsections (3.1 and 3.2), the exact mechanism to extract spice circuit has been described.

\section{Patch Antenna Planar Design}

A patch antenna with its resonating frequency at $5 \mathrm{GHz}$ has been designed and is shown in Figure 12. Similarly a patch antenna with CSRR loading for its resonance frequency at $5 \mathrm{GHz}$ has been designed and is shown in Figure 13. The return loss of the $5 \mathrm{GHz}$ resonating patch with and without CSRR loading has been plotted in Figure 14. The copper conductive patch element without CSRR loading has dimension of $13.9 \mathrm{~mm} \times 18 \mathrm{~mm} \times 0.017 \mathrm{~mm}$ with its inset feed of $13.05 \mathrm{~mm} \times 2.8 \mathrm{~mm} \times 0.017 \mathrm{~mm}$ and inset gap of $0.5 \mathrm{~mm}$. This patch element has been laid over $30 \mathrm{~mm} \times 30 \mathrm{~mm} \times 1.57 \mathrm{~mm} \mathrm{Fr} 4$ substrate with its relative permittivity 4.4 and tangent loss of 0.02 while the ground layer has been designed using copper conductor with its dimension of $30 \mathrm{~mm} \times 30 \mathrm{~mm} \times 0.017$ $\mathrm{mm}$. While the copper conductive patch element with CSRR loading has dimension of $5.3 \mathrm{~mm} \times 13 \mathrm{~mm} \times 0.017 \mathrm{~mm}$ with its inset feed of $7.35 \mathrm{~mm} \times 2.8 \mathrm{~mm} \times$ $0.017 \mathrm{~mm}$ and inset gap of $0.5 \mathrm{~mm}$. This patch element has been laid over 20 $\mathrm{mm} \times 15 \mathrm{~mm} \times 1.57 \mathrm{~mm}$ Fr4 substrate with its relative permittivity 4.4 and tangent loss of 0.02 while the ground layer has been designed using copper conductor with its dimension of $20 \mathrm{~mm} \times 15 \mathrm{~mm} \times 0.017 \mathrm{~mm}$. Thus the application of CSRR loading reduces the patch antenna size by $72.5 \%$ while improving the gain and directivity. 


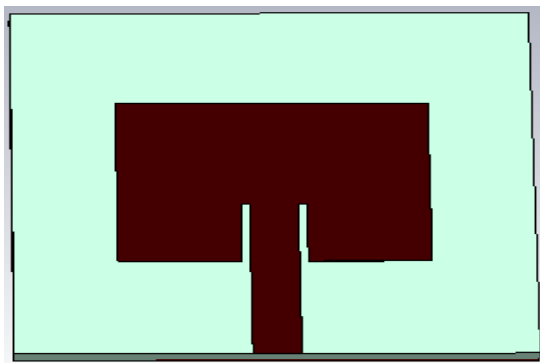

Figure 12. Patch antenna without CSRR.

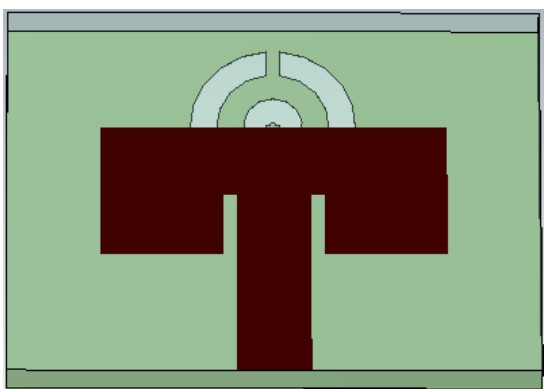

Figure 13. Patch antenna with CSRR.

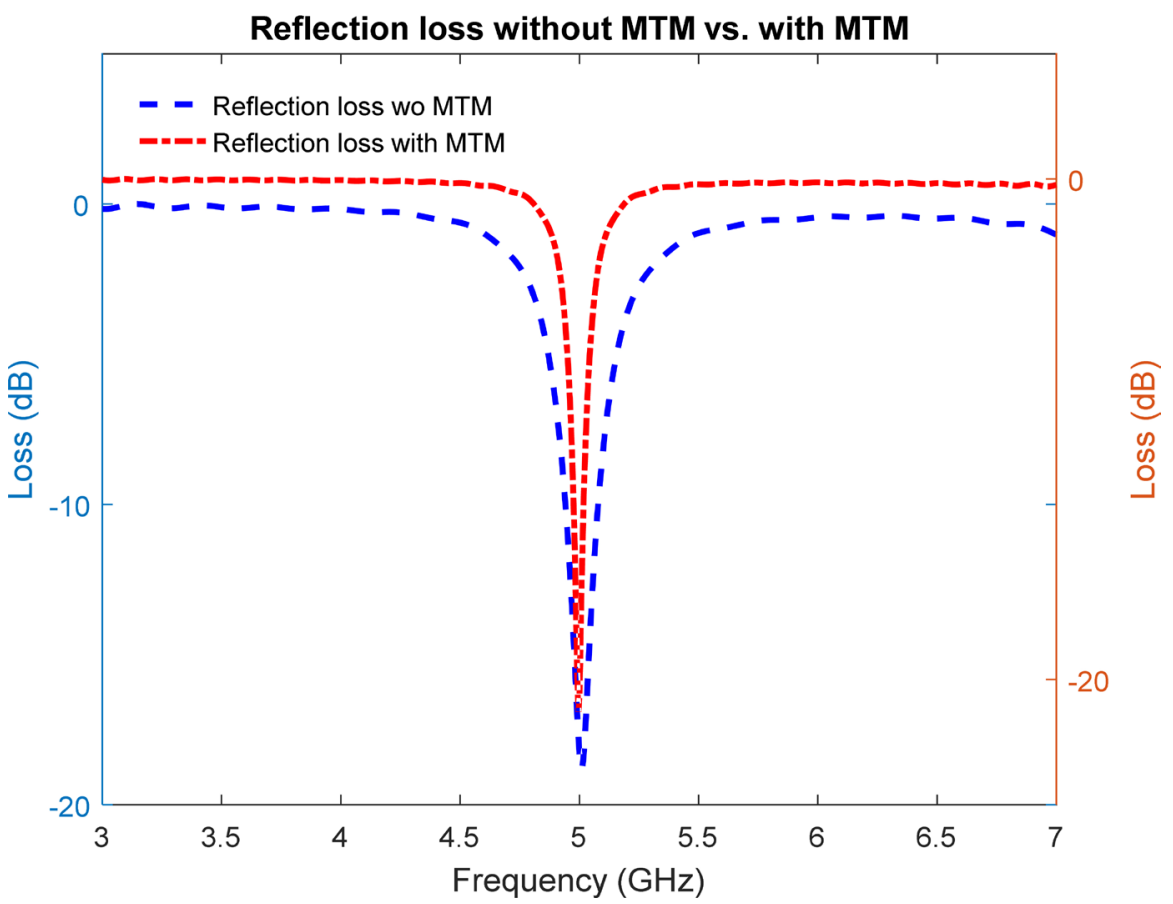

Figure 14. Reflection loss for planar patch with and without CSRR loading.

\subsection{Equivalent Spice Circuit for Patch without CSRR}

An equivalent spice circuit parameters for the patch antenna without CSRR has been derived using Matlab and ADS and its original and fitted response for the magnitude and phase of the S11 parameter has been plotted in Figure 15 and Figure 16. 


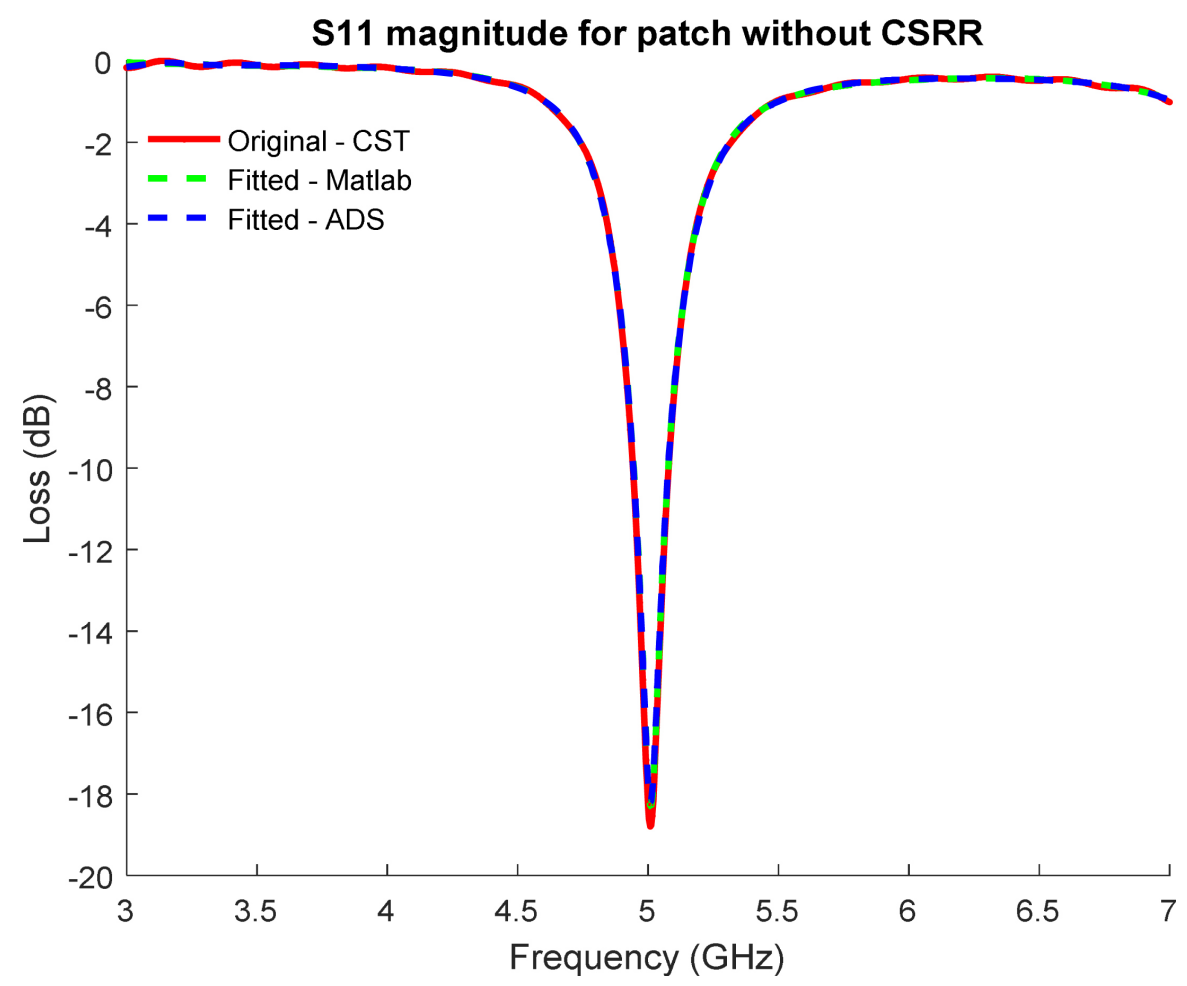

Figure 15. S11 original and fitted magnitude.

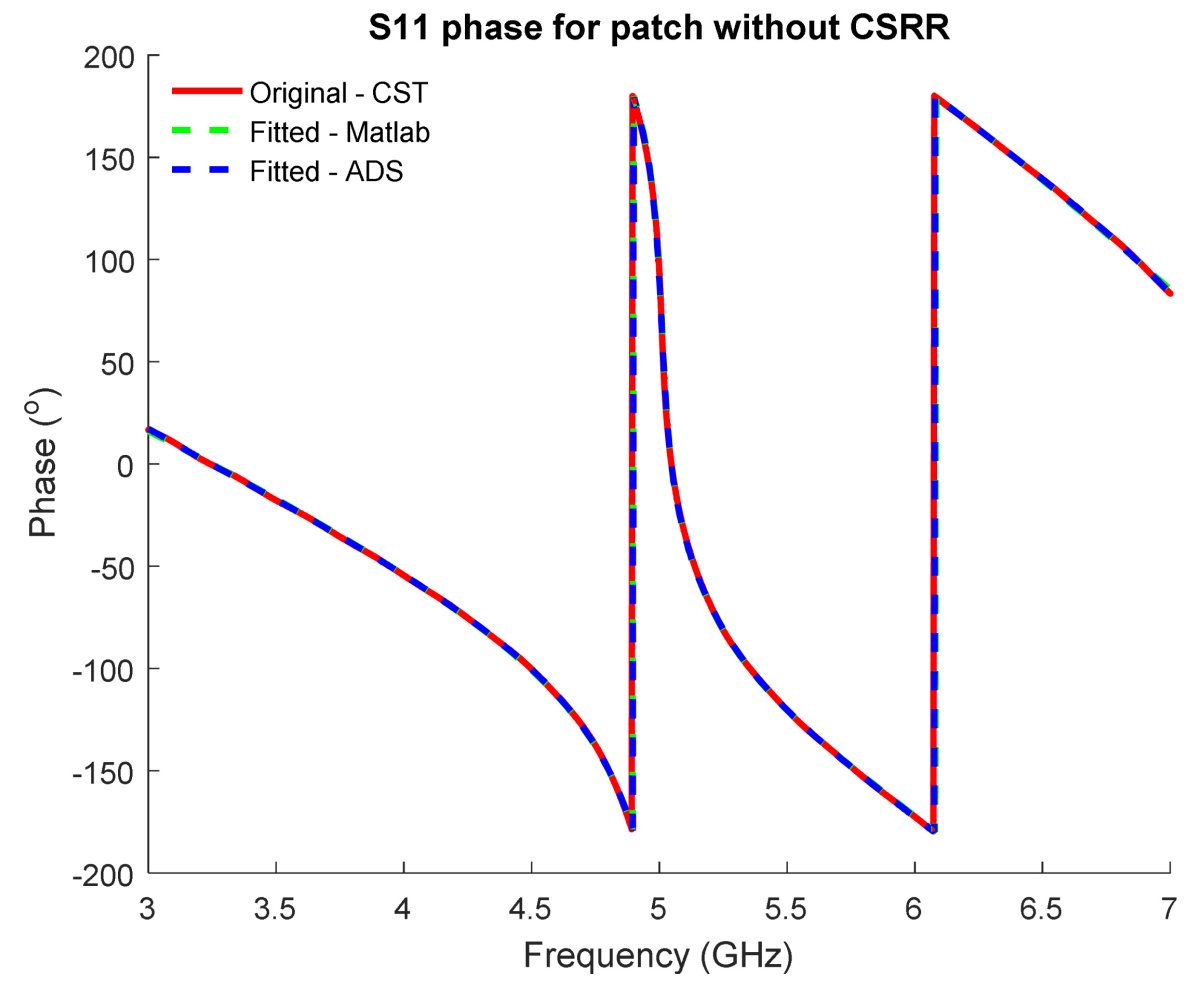

Figure 16. S11 original and fitted phase. 
Table 2. Poles and Residues for patch without CSRR.

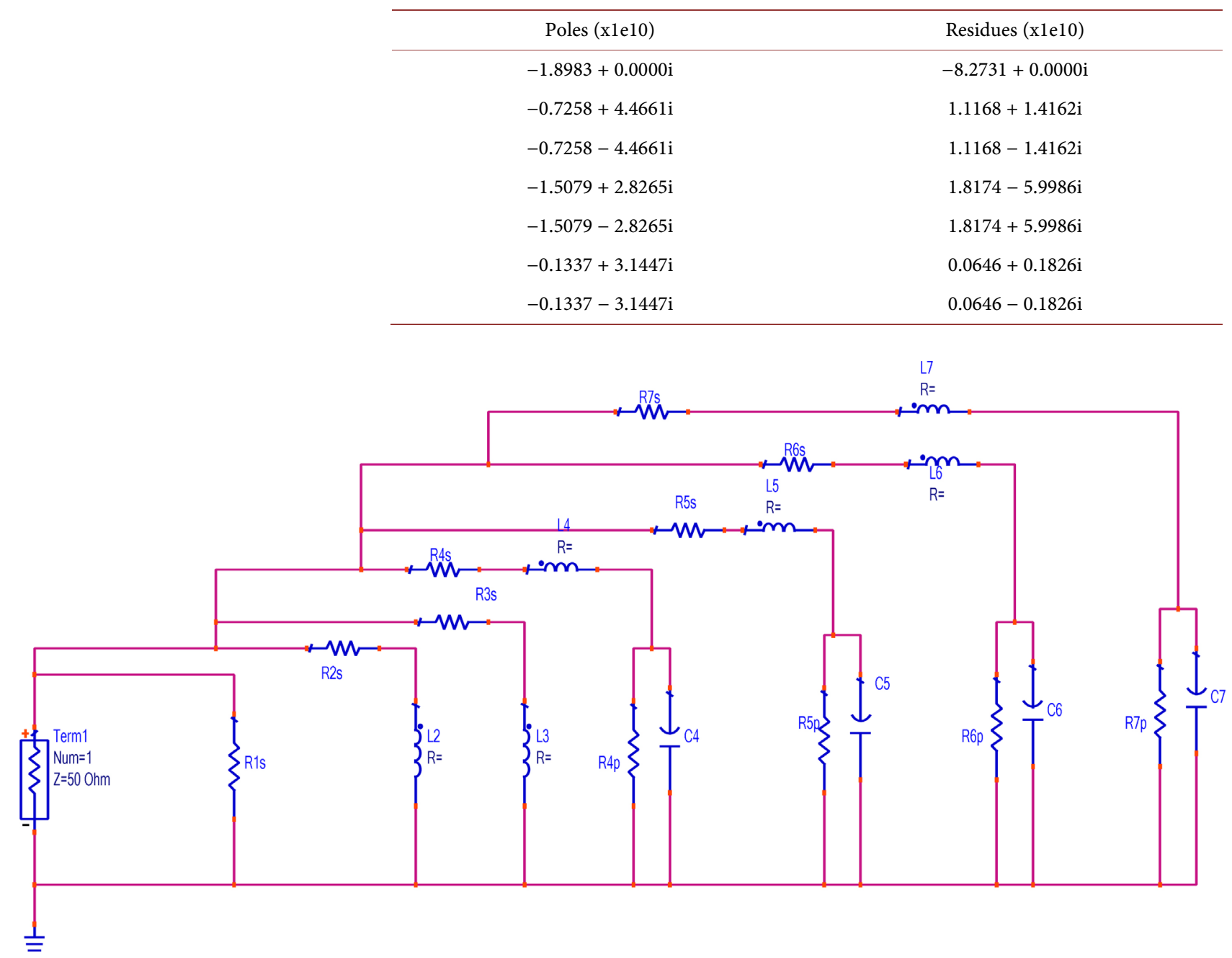

Figure 17. Spice circuit for patch antenna without CSRR.

Table 3. RLC parameters for the spice circuit.

\begin{tabular}{|c|c|c|c|c|c|c|c|}
\hline \multicolumn{2}{|c|}{ RLC parameters } & \multicolumn{2}{|c|}{ Stage 1} & \multicolumn{2}{|c|}{ Stage 2} & & Stage 3 \\
\hline \multicolumn{2}{|c|}{$\mathrm{R}_{\mathrm{s}}(\mathrm{i})(\Omega)$} & \multicolumn{2}{|c|}{47.4196874758007} & \multicolumn{2}{|c|}{-49.4951867330331} & \multicolumn{2}{|c|}{6.59797520504911} \\
\hline \multicolumn{2}{|c|}{$\mathrm{L}(\mathrm{i})(\mathrm{nH})$} & & & \multicolumn{2}{|c|}{-0.791165097589256} & & 13690996402107 \\
\hline \multicolumn{8}{|c|}{$\mathrm{C}(\mathrm{i})(\mathrm{fF})$} \\
\hline \multicolumn{8}{|c|}{$\mathrm{R}_{\mathrm{p}}(\mathrm{i})(\mathrm{K} \Omega)$} \\
\hline $\begin{array}{c}\text { RLC } \\
\text { parameters }\end{array}$ & & Stage 4 & & & Stage 6 & & Stage 7 \\
\hline $\mathrm{R}_{\mathrm{s}}(\mathrm{i})(\Omega)$ & 1898 & 8.13244138526 & -0.3016 & 05321984 & 27876.96732759 & & 65.4578642997689 \\
\hline $\mathrm{L}(\mathrm{i})(\mathrm{nH})$ & 13.83 & 318619464049 & 3.3115 & 6158249 & -4697.028752669 & & 16.3993795128067 \\
\hline $\mathrm{C}(\mathrm{i})(\mathrm{fF})$ & 3.630 & 066382691226 & 207.10 & 197176 & -0.486566150764 & & 64.4514696059679 \\
\hline $\mathrm{R}_{\mathrm{p}}(\mathrm{i})(\mathrm{K} \Omega)$ & -2.17 & 7661776344493 & 10.207 & 3987675 & -274.1117217031 & & -5.11425776117095 \\
\hline
\end{tabular}


The poles and residues derived using a rational function from Matlab with the data of S11 parameter from CST tool has been shown in Table 2. The poles and residues have been equated to RLC parameters after the S-parameter conversion to $\mathrm{ABCD}$ parameters and equating the transfer function to the admittance. Similarly ADS tool has been used to extract the spice parameters while passivity is enforced. The equivalent spice circuit has been shown in Figure 17 while the individual RLC value has been shown in Table 3. The magnitude and phase plot in Figure 15 and Figure 16 show that fitted parameters provide the same response of the spice circuit to its field solver tool response, thus the spice circuit can be used for its equivalence.

\subsection{Equivalent Spice circuit for Patch with CSRR}

Similarly the original and fitted plot comparison for the magnitude and phase of the S11 parameter for the patch antenna loaded with CSRR has been shown in Figure 18 and Figure 19. The fitted plot has been obtained after deriving the RLC parameters of the equivalent spice circuit. The poles and residues derived from a rational function using Matlab has been shown in Table 4.

Figure 20 shows the obtained equivalent spice circuit using ADS tool and the RLC values have been shown in Table 5 .

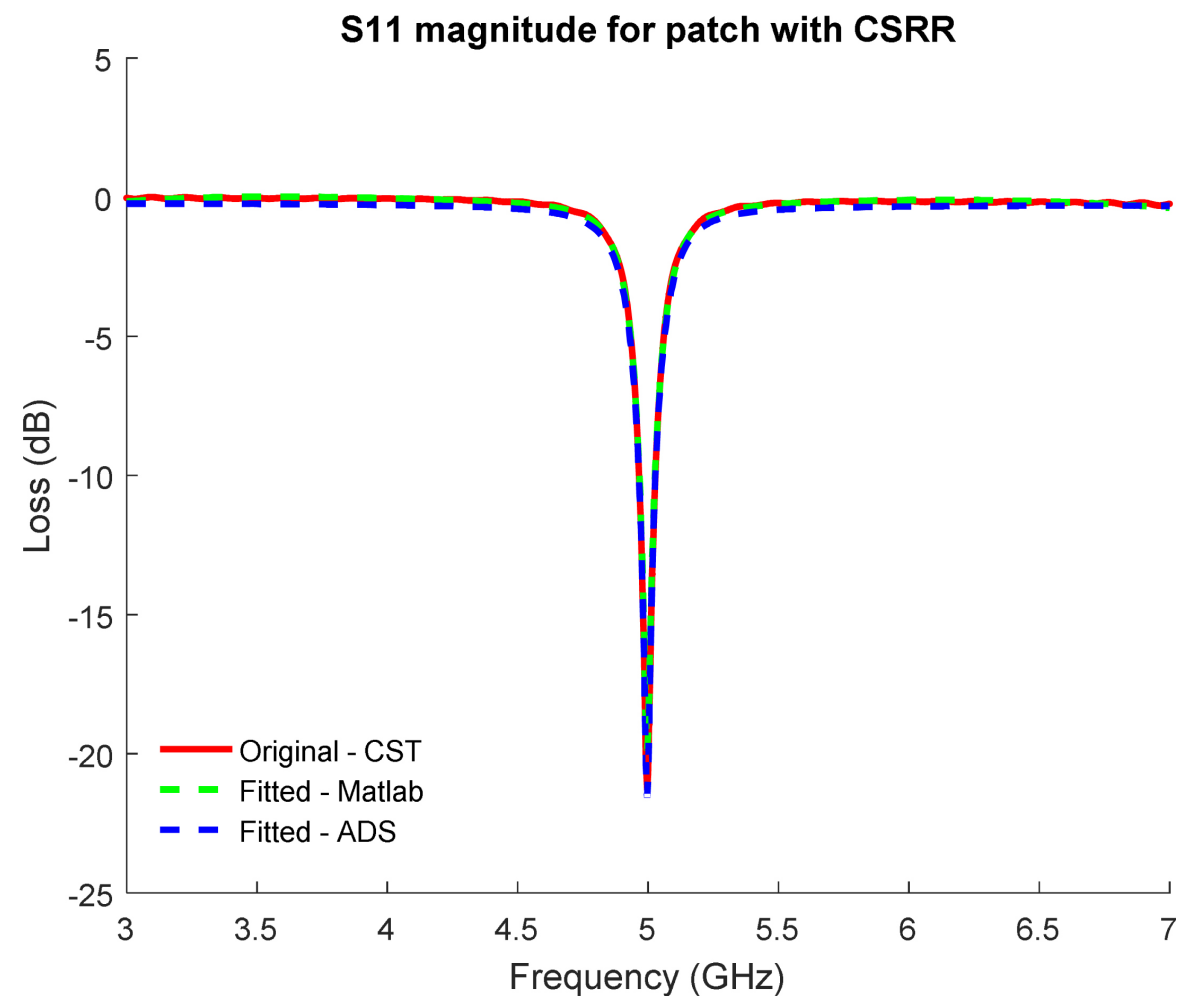

Figure 18. S11 original and fitted magnitude. 


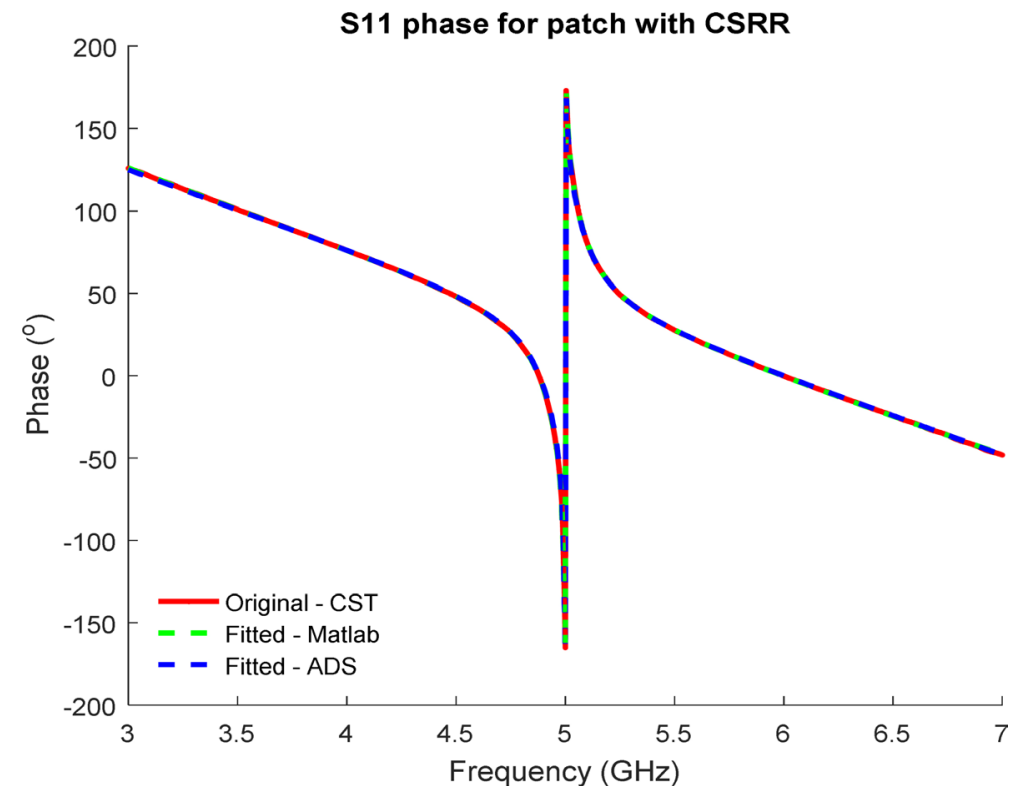

Figure 19. S11 original and fitted phase.

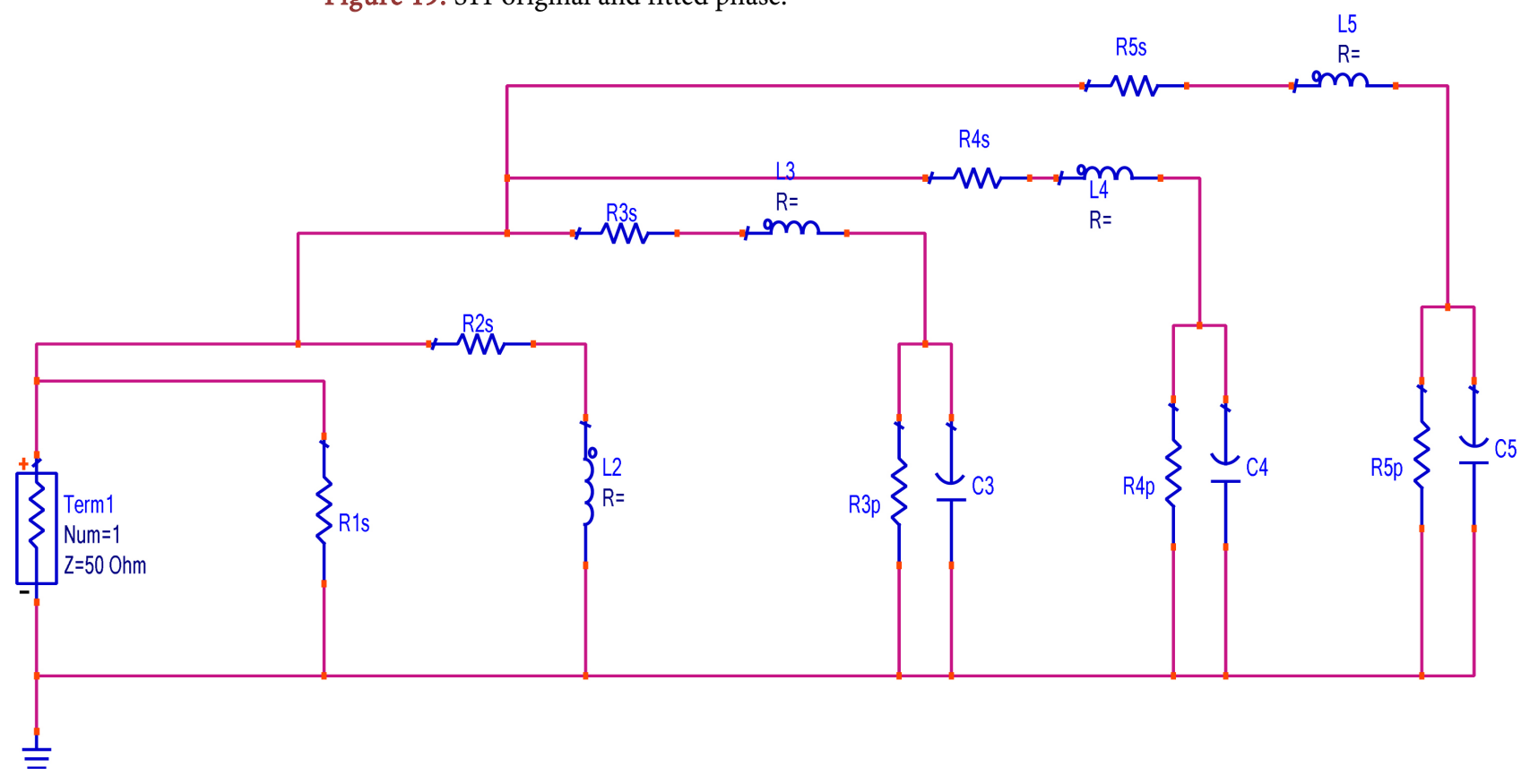

Figure 20. Spice circuit for patch antenna with CSRR.

Table 4. Poles and Residues for patch with CSRR.

\begin{tabular}{cc}
\hline Poles $(\mathrm{x} 1 \mathrm{e} 10)$ & Residues (x1e10) \\
\hline$-1.5660+4.2981 \mathrm{i}$ & $1.5002-2.7614 \mathrm{i}$ \\
$-1.5660-4.2981 \mathrm{i}$ & $1.5002+2.7614 \mathrm{i}$ \\
$-0.0586+3.1388 \mathrm{i}$ & $-0.0534-0.0429 \mathrm{i}$ \\
$-0.0586-3.1388 \mathrm{i}$ & $-0.0534+0.0429 \mathrm{i}$ \\
$-1.2630+1.4337 \mathrm{i}$ & $-2.7321-0.6150 \mathrm{i}$ \\
$-1.2630-1.4337 \mathrm{i}$ & $-2.7321+0.6150 \mathrm{i}$
\end{tabular}


Table 5. RLC parameters for Spice circuit.

\begin{tabular}{|c|c|c|c|}
\hline & Stage 1 & Stage 2 & Stage 3 \\
\hline $\mathrm{R}_{\mathrm{s}}(\mathrm{i})(\Omega)$ & 50 & -60.9194134324259 & 41.8363527812994 \\
\hline $\mathrm{L}(\mathrm{i})(\mathrm{nH})$ & & -0.511830216374149 & 1.52315549511506 \\
\hline $\mathrm{C}(\mathrm{i})(\mathrm{pF})$ & & & 0.149219979459191 \\
\hline \multirow[t]{2}{*}{$\mathrm{R}_{\mathrm{p}}(\mathrm{i})(\mathrm{K} \Omega)$} & & & -0.312687492847095 \\
\hline & & Stage 4 & Stage 5 \\
\hline \multicolumn{2}{|c|}{$\mathrm{R}_{s}(\mathrm{i})(\Omega)$} & 0.542995516359006 & 21.2973424540247 \\
\hline \multicolumn{2}{|c|}{$\mathrm{L}(\mathrm{i})(\mathrm{nH})$} & 2.07841688542428 & 71.1998803684241 \\
\hline \multicolumn{2}{|c|}{$\mathrm{C}(\mathrm{i})(\mathrm{pF})$} & 3.12416821215986 & 0.014152013972141 \\
\hline \multicolumn{2}{|c|}{$\mathrm{R}_{\mathrm{p}}(\mathrm{i})(\mathrm{K} \Omega)$} & 6.74554026316824 & 290.922619952124 \\
\hline
\end{tabular}

\section{Patch Antenna Bend Design}

Patch antenna with and without CSRR loading has been bent with a radius of 20 $\mathrm{mm}$ and $40 \mathrm{~mm}$ to show the effect of bending. The bend structures have been shown in Figure 21 and Figure 22, while the comparison of the return loss has been plotted in Figure 23.

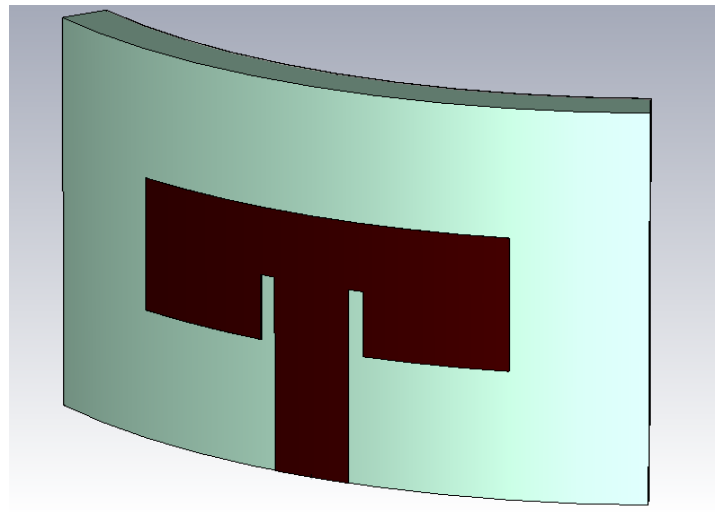

Figure 21. Bend patch configuration.

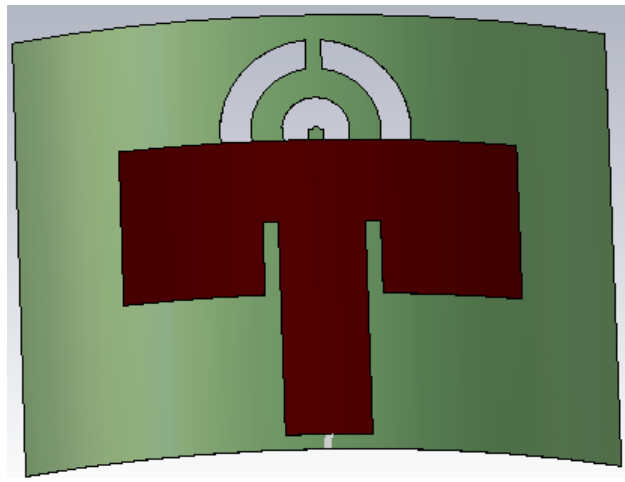

Figure 22. Bend patch configuration. 


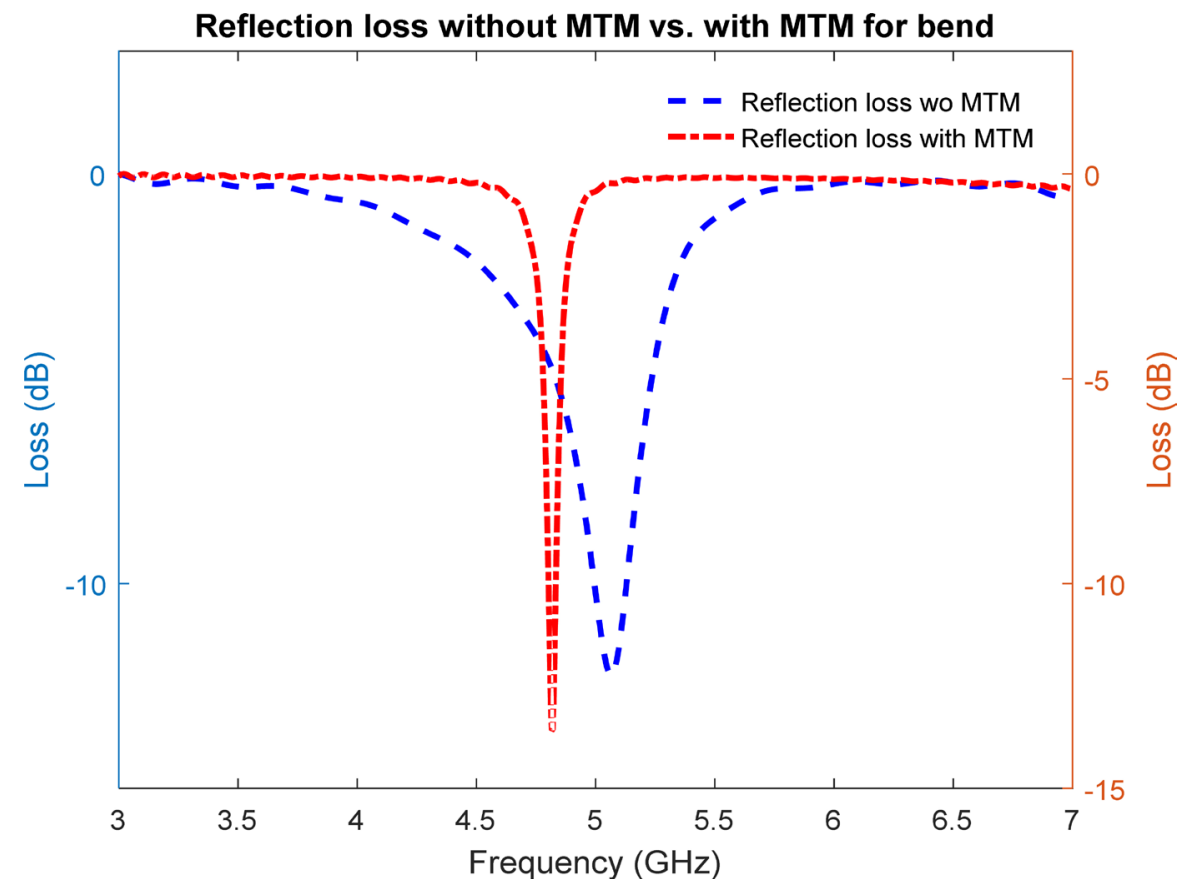

Figure 23. Reflection loss for bend patch without and with CSRR loading.

\section{CSRR Loading Effect on Resonance Frequency for Patch Antenna}

The patch configuration as defined in Section 3 has been used for the CSRR loading effect over its resonance frequency. Here the patch element has dimension of $13.9 \mathrm{~mm} \times 18 \mathrm{~mm} \times 0.017 \mathrm{~mm}$ with its inset feed of $13.05 \mathrm{~mm} \times 2.8 \mathrm{~mm}$ $\times 0.017 \mathrm{~mm}$ and inset gap of $0.5 \mathrm{~mm}$. This patch element has been laid over 30 $\mathrm{mm} \times 30 \mathrm{~mm} \times 1.57 \mathrm{~mm}$ Fr4 substrate with its relative permittivity 4.4 and tangent loss of 0.02 while the ground layer has been designed using copper conductor with its dimension of $30 \mathrm{~mm} \times 30 \mathrm{~mm} \times 0.017 \mathrm{~mm}$. Figure 12 shows the patch configuration without CSRR loading while Figure 24 (Top view) and Figure 25 (Bottom view) show the same size patch configuration with CSRR loading. The CSRR loading as shown in Figure 26 provides resonance frequency shift where the original patch resonates at $5 \mathrm{GHz}$ while the periodic CSRR array loaded patch resonates at $3.7 \mathrm{GHz}$.

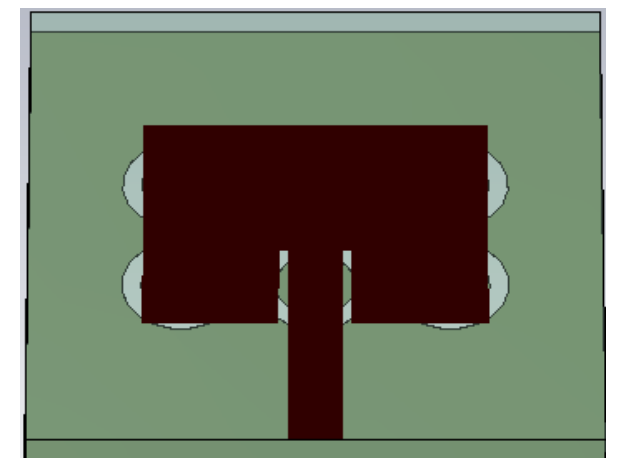

Figure 24. Patch antenna with CSRR (Top side). 


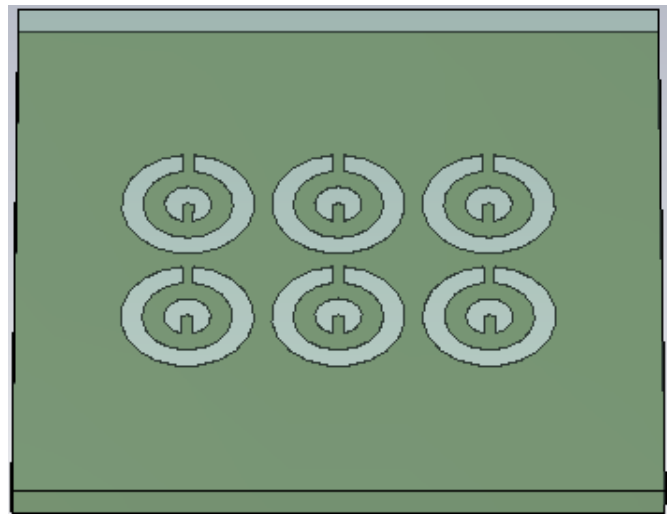

Figure 25. Patch antenna with CSRR (Bottom side).

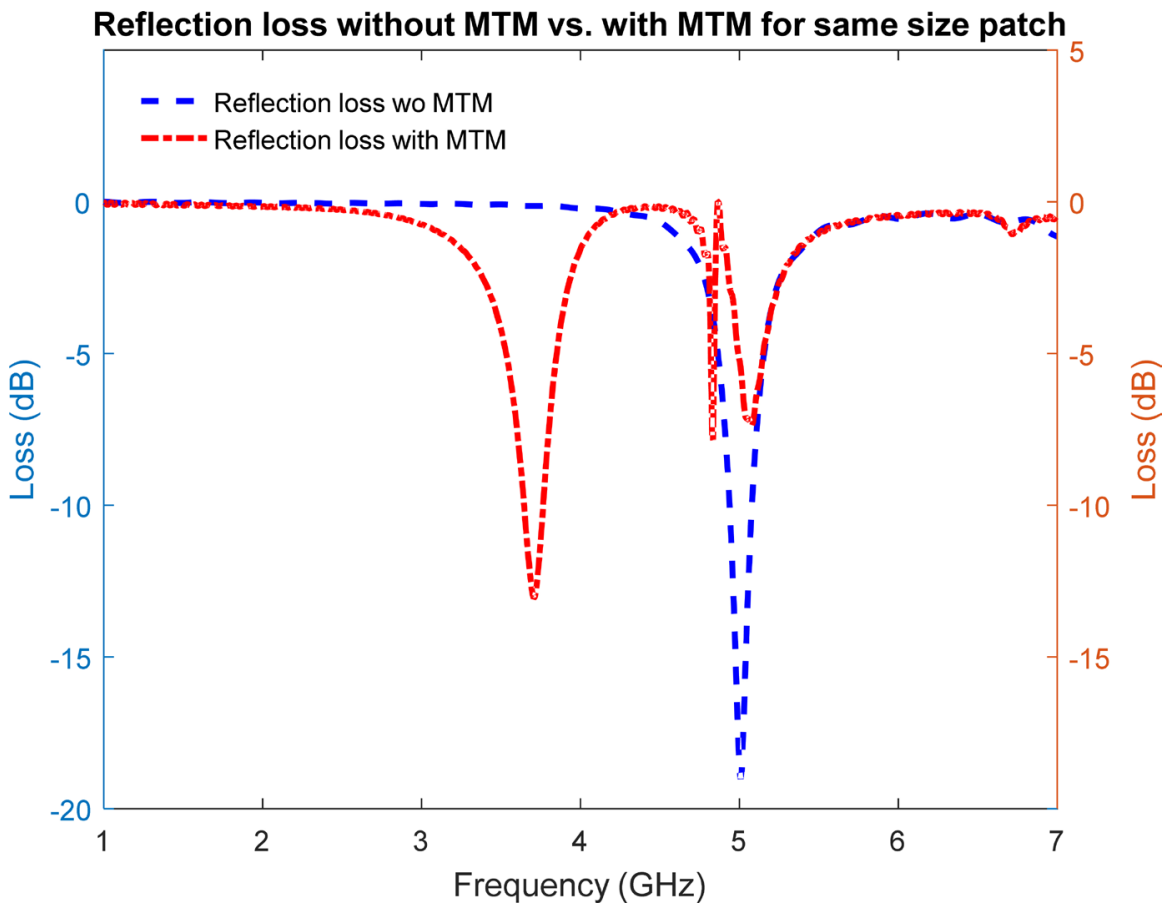

Figure 26. Reflection loss for patch with and without CSRR loading.

\section{Simulation Results}

Table 6 shows the comparison of antenna parameters when patch is not loaded with CSRR and when patch is loaded with CSRR. The parameter for the bend configuration of these elements has also been shown here. The bending of the patch antenna shows a shift in resonance frequency with an increase in efficiency and gain. As shown here, although the CSRR loading provides an effective mechanism for miniaturization ( $72.5 \%$ patch size reduction) in patch element, it decreases the gain while providing excellent radiation efficiency.

Table 7 shows the comparison of antenna parameters when the patch size is maintained while loading the CSRR with the patch element without loading the CSRR. Here a lowering in resonance frequency has been observed when the patch element is loaded with CSRR periodic array. 
Table 6. Patch antenna parameters (with and without CSRR loading).

\begin{tabular}{ccccccccc}
\hline & Patch & $\begin{array}{c}\text { Freq }\left(f_{\mathrm{o}}\right) \\
\text { in GHz }\end{array}$ & $\begin{array}{c}\text { Bandwidth } \\
(\mathrm{MHz})\end{array}$ & S11 (dB) & VSWR & $\begin{array}{c}\text { Gain } \\
(\mathrm{dB})\end{array}$ & $\begin{array}{c}\text { Angular } \\
\text { width }\left({ }^{\circ}\right)\end{array}$ & $\begin{array}{c}\text { Radiation } \\
\text { Efficiency } \\
(\%)\end{array}$ \\
\hline $\begin{array}{c}\text { Without } \\
\text { CSRR }\end{array}$ & Planar & 5.0 & 136.4 & -18.8 & 1.26 & 5.16 & 46.8 & 87.22 \\
Bith & Planar & 5.064 & 135 & -12.23 & 1.65 & 6.11 & 48.1 & 98.30 \\
CSRR & Bend & 4.892 & 61.8 & -20.72 & 1.20 & 2.11 & 82.2 & 85.10 \\
\hline
\end{tabular}

Table 7. Patch antenna parameters (with and without CSRR loading on same size patch).

\begin{tabular}{ccccccccc}
\hline & Patch & $\begin{array}{c}\text { Freq }\left(\mathrm{f}_{\mathrm{o}}\right) \\
\text { in GHz }\end{array}$ & $\begin{array}{c}\text { Bandwidth } \\
(\mathrm{MHz})\end{array}$ & S11 (dB) & VSWR & $\begin{array}{c}\text { Gain } \\
(\mathrm{dB})\end{array}$ & $\begin{array}{c}\text { Angular } \\
\text { width }\left(^{\circ}\right)\end{array}$ & $\begin{array}{c}\text { Radiation } \\
\text { Efficiency } \\
(\%)\end{array}$ \\
\hline $\begin{array}{c}\text { Without } \\
\text { CSRR }\end{array}$ & Planar & 5.0 & 136.4 & -18.8 & 1.26 & 5.16 & 46.8 & 87.22 \\
$\begin{array}{c}\text { With } \\
\text { CSRR }\end{array}$ & Planar & 3.7 & 118.9 & -12.97 & 1.58 & 3.77 & 50.4 & 93.15 \\
\hline
\end{tabular}

\section{Conclusion}

The paper provides a simple mechanism to miniaturize the patch antenna with the CSRR loading for its fixed resonance and show the effect of CSRR loading in the resonance frequency for the original patch size. The design has shown that the loading of CSRR reduces the patch size by $72.5 \%$ while loading the CSRR for the same size patch lowers the resonant frequency by $26 \%$. Although the full field solver tool provides a circuit response within its $3 \mathrm{D}$ environment, the simulation is slow and resource consuming. A spice circuit for these circuits can be an alternative for its use in any spice circuit simulation tool. Hence, an equivalent spice circuit and RLGC parameters for the CSRR, patch antenna with and without CSRR loading have been obtained for its inclusion in electrical circuit.

\section{Acknowledgements}

The author would like to acknowledge the CSIC at Department of Engineering, University of Cambridge for providing the necessary support and funding for the project. This project was completed as part of the supervision to UROP projects.

\section{References}

[1] Pozar, D.M. and Schaubert, D.H. (1995) Microstrip Antennas. John Wiley \& Sons Ltd., Hoboken. https://doi.org/10.1109/9780470545270

[2] Pendry, J.B., Holden, A.J., Robbins, D.J. and Stewart, W.J. (1998) Low-Frequency Plasmons in Thin Wire Structures. Journal of Physics Condensed Matter, 10, 4785-4809. https://doi.org/10.1088/0953-8984/10/22/007

[3] Veselago, V.G. (1968) The Electrodynamics of Substances with Simultaneously 
Negative Values of $\varepsilon$ and $\mu$. Soviet Physics Uspekhi, 10, 509-514. https://doi.org/10.1070/PU1968v010n04ABEH003699

[4] Dong, Y., Toyao, H. and Itoh, T. (2012) Design and Characterization of Miniaturized Patch Antennas Loaded with Complementary Split-Ring Resonators. IEEE transactions on Antennas and Propagation, 60, 772-785. https://doi.org/10.1109/TAP.2011.2173120

[5] Erentok, A. and Ziolkowski, R.W. (2008) Metamaterial-Inspired Efficient Electrically Small Antennas. IEEE Transactions on Antennas and Propagation, 56, 691-707. https://doi.org/10.1109/TAP.2008.916949

[6] Ziolkowski, R.W., Jin, P. and Lin, C.C. (2011) Metamaterial-Inspired Engineering. IEEE Proceedings of Antennas, 99, 1720-1731.

https://doi.org/10.1109/JPROC.2010.2091610

[7] Garg, R., Bhartia, P., Bahl, I. and Ittipiboon, A. (2001) Microstrip Antenna Design Handbook. Artech House, Boston.

[8] Pendry, J.B., Holden, A.J., Robbins, D.J. and Stewart, W.J. (1999) Magnetism from Conductors and Enhanced Nonlinear Phenomena. IEEE Transactions on Microwave Theory and Techniques, 47, 2075-2084. https://doi.org/10.1109/22.798002

[9] Smith, D.R. and Kroll, N. (2000) Negative Refractive Index in Left-Handed Materials. Physical Review Letters, 85, 2933-2936.

https://doi.org/10.1103/PhysRevLett.85.2933

[10] Shelby, A. Smith, D.R. and Schultz, S. (2001) Experimental Verification of a Negative Index of Refraction. Science, 292, 77-79. https://doi.org/10.1126/science.1058847

[11] Smith, D.R., Padilla, W.J., Vier, D.C., Nemat-Nasser, S.C. and Schultz, S. (2000) Composite Medium with Simultaneously Negative Permeability and Permittivity. Physical Review Letters, 84, 4184-4187. https://doi.org/10.1103/PhysRevLett.84.4184

[12] Ramzan, M. and Topalli, K. (2015) A Miniaturized Patch Antenna by Using a CSRR Loading Plane. International Journal of Antennas and Propagation, 1-9. https://doi.org/10.1155/2015/495629

[13] Umadevi, K.S., Chakyar, S.P., Simon, S.K., Andrews, J. and Joseph, V.P. (2017) Split Ring Resonators Made of Conducting Wires for Performance Enhancement. Europhysics Letters, 118, 24002. https://doi.org/10.1209/0295-5075/118/24002

[14] Castro, P.J., Barroso, J.J., Neto, J.P.L., Tomaz, A. and Hasar, U.C. (2016) Experimental Study of Transmission and Reflection Characteristics of a Gradient Array of Metamaterial Split-Ring Resonators. Journal of Microwaves, Optoelectronics and Electromagnetic Applications, 15, 380-389. https://doi.org/10.1590/2179-10742016v15i4658

[15] Li, D., Yu, J., Zhou, W., Ji, B., Song, B. and Guo, X. (2015) An Analytical Model for Resonant Frequency of the Split Ring Resonators. 8th Europe, China Millimeter Waves and THz Technology Workshop, Cardiff, 14-15 September 2015, 1-3. https://doi.org/10.1109/UCMMT.2015.7460632

[16] Schuette, D., Irfanullah, I., Nariyal, S., Khattak, S. and Braaten, B.D. (2016) Strong Coupling (Crosstalk) between Printed Microstrip and Complementary Split Ring Resonator (CSRR) Loaded Transmission Lines in Multilayer Printed Circuit Boards (PCB). IEEE International Conference on Electro Information Technology (EIT), Grand Forks, 196-199. https://doi.org/10.1109/EIT.2016.7535239

[17] Gustavsen, B. and Semlyen, A. (1999) Rational Approximation of Frequency Domain Responses by Vector Fitting. IEEE Transactions on Power Delivery, 14, 1052-1061. https://doi.org/10.1109/61.772353 
Submit or recommend next manuscript to SCIRP and we will provide best service for you:

Accepting pre-submission inquiries through Email, Facebook, LinkedIn, Twitter, etc. A wide selection of journals (inclusive of 9 subjects, more than 200 journals)

Providing 24-hour high-quality service

User-friendly online submission system

Fair and swift peer-review system

Efficient typesetting and proofreading procedure

Display of the result of downloads and visits, as well as the number of cited articles Maximum dissemination of your research work

Submit your manuscript at: http://papersubmission.scirp.org/

Or contact ojapr@scirp.org 